Studi Akuntansi \& Keuangan Indonesia

\title{
Pengaruh Penurunan Tarif Pajak Terhadap Modal Saham Bank
}

\author{
Adrian Teja \\ Program Studi Manajemen Keuangan, Universitas Prasetiya Mulya \\ BSD City Kavling, Jl. Edutown Jl. BSD Raya Utama No.1, BSD City, Kec. Pagedangan, Tangerang, \\ Banten 15339
}

\section{Kata kunci:}

Modal saham bank, struktur modal, penghematan pajak dari utang, tarif pajak penghasilan badan

\section{Keywords: \\ Bank equity, capital structure, debt tax saving, corporate income tax rates.}

\section{Corresponding author:} adrian.teja@pmbs.ac.id

\begin{abstract}
ABSTRAK
Tujuan penelitian ini adalah menemukan pengaruh penurunan tarif pajak penghasilan badan terhadap modal saham bank. Teori struktur modal menyatakan tarif pajak yang lebih rendah mengurangi manfaat pajak dari utang. Dengan demikian, penurunan tarif pajak akan meningkatkan modal bank. Pengujian hipotesis dilakukan dengan menggunakan metode regresi crosssection. Variabel terikat adalah rasio modal bank terhadap total aset. Variabel bebas adalah perubahan tarif pajak dari $30 \%$ menjadi $28 \%$ dan $28 \%$ menjadi $25 \%$ pada tahun 2008-2010. Penelitian ini menemukan penurunan tarif pajak penghasilan bank berpengaruh pada penurunan rasio modal saham bank terhadap total aset. Bank Indonesia harus menerbitkan regulasi untuk menghambat kecenderungan bank untuk mengambil resiko dan memperkuat modal saham bank.
\end{abstract}

\section{ABSTRACT}

The research objective is to find the effect of declining corporate income tax rates on bank equity. Capital structure theory suggests that lower corporate income tax rates will reduce the tax benefit of debt financing. Hence, declining corporate income tax rates will increase bank equity. We test the hypothesis using cross-section regression. The dependent variable is the equity to total bank assets ratio. The independent variable is a change in Indonesia corporate tax from $30 \%$ to $28 \%$ and $28 \%$ to $25 \%$ for $2008-2010$. We find that declining corporate income tax rates reduce the ratio of the bank equity to total asset. Bank Indonesia has to issue a regulation that prevents risk-taking tendencies and supports higher bank equity. 


\section{Pendahuluan}

Tarif pajak penghasilan badan di Indonesia mengalami penurunan dari 30\% tahun 2008 menjadi $28 \%$ tahun 2009 dan 25\% tahun 2010 (Undang-Undang Republik Indonesia, 2008). Tujuan penurunan tarif pajak penghasilan badan adalah meningkatkan daya saing negara Indonesia untuk menarik Foreign Direct Investment (FDI) relatif negara lain. Penurunan tarif pajak penghasilan badan merupakan realisasi persaingan perpajakan antar negara dalam menarik FDI (Afrianto, 2018; Kato, 2015; Suzuki, 2014). Pada gambar 1 dapat dilihat penurunan tarif pajak penghasilan badan secara efektif telah meningkatkan nilai FDI di Indonesia.

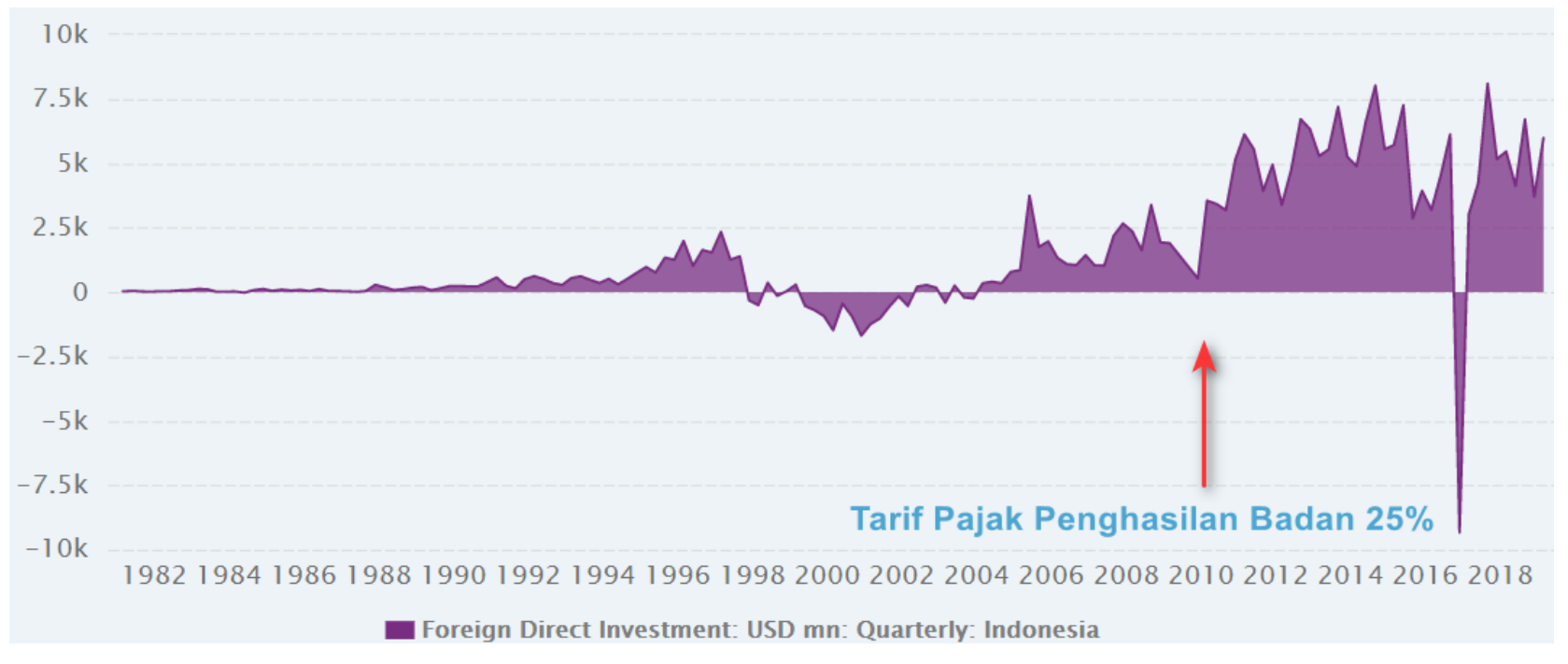

Sumber: CEIC

Gambar 1. Foreign Direct Investment Indonesia

Walaupun penurunan tarif pajak penghasilan badan berhasil meningkatkan arus FDI ke Indonesia, penelitian mengenai pengaruh penurunan tarif pajak penghasilan badan terhadap struktur modal bank di Indonesia belum dilakukan. Penelitian mengenai pengaruh penurunan tarif pajak terhadap struktur modal bank dibutuhkan karena hasil penelitian yang ada masih menghasilkan temuan yang beragam.

Pemberian insentif pajak untuk meningkatkan modal saham direspon dengan baik oleh bank di Eropa (Martin-flores \& Moussu, 2017; Schepens, 2016). Bank yang beroperasi pada negara Eropa yang mengenakan tarif pajak penghasilan badan yang tinggi tidak bereaksi pada insentif pajak untuk mengurangi utang (Bremus, Schmidt, \& Tonzer, 2020). Tarif pajak yang tinggi mendorong bank di Amerika Serikat untuk menggunakan utang lebih banyak (Horváth, 2020). Demikian pula sebaliknya, penurunan tarif pajak telah mendorong bank di Italia untuk mengurangi non-deposit debt ratios atau menambah utang bank (Gambacorta, Ricotti, Sundaresan, \& Wang, 2018). Perubahan tingkat utang pada bank di Amerika Serikat akibat peningkatan dan penurunan tarif pajak penghasilan badan tidak simetris (Heider \& Ljungqvist, 2015). Bank meningkatkan tingkat utang ketika tarif pajak penghasilan badan ditingkatkan. Tetapi, bank tidak menurunkan tingkat utang ketika tarif pajak penghasilan badan diturunkan.

Hasil penelitian diatas menunjukkan pengaruh perubahan tarif pajak terhadap modal saham bank belum memberikan hasil yang konsisten. Oleh karena itu, penelitian lebih lanjut terkait pengaruh perubahan tarif pajak terhadap modal saham bank dibutuhkan. Dengan demikian, kontribusi dari penelitian ini yaitu pertama, melakukan penelitian pengaruh penurunan tarif pajak penghasilan badan terhadap modal saham bank di Indonesia yang masih belum dilakukan oleh peneliti lain. Penelitian difokuskan pada modal saham bank relatif total aset bank. Analisis pada modal saham bank memberikan informasi langsung pada peningkatan rasio kecukupan modal bank (CAR - Capital Adequacy Ratio). Pembahasan mengenai kesehatan bank lebih banyak diukur dari rasio kecukupan modal daripada besarnya utang dari bank. Kedua, penurunan tarif pajak adalah peristiwa yang langka. Oleh karena itu, pemahaman mengenai pengaruh penurunan tarif pajak ini belum sepenuhnya dipahami. Dan ketiga, menambah bukti uji empiris mengenai pengaruh penurunan tarif pajak penghasilan badan terhadap modal saham bank di negara dengan tingkat inklusi keuangan masyarakat masih relatif rendah. Ummah, Nuryartono, dan Anggraeni (2012) menemukan inklusi 
Studi Akuntansi \& Keuangan Indonesia

keuangan di Indonesia masih sangat rendah. Inklusi keuangan yang rendah menunjukkan potensi pertumbuhan bisnis bank yang sangat tinggi.

Pertanyaan penelitian yang diajukan adalah "Apakah pengaruh penurunan pajak penghasilan badan terhadap penguatan modal bank?" Manfaat penelitian ini adalah pemerintah dapat memahami eksternalitas penurunan tarif pajak penghasilan badan pada perbankan di Indonesia. Heckemeyer dan De Mooij (2017) berpendapat perubahan tingkat utang perbankan mempunyai implikasi pada perubahan resiko sistemik dari bank. Penelitian ini juga sangat penting mengingat trend kompetisi pajak antar negara melalui penurunan tarif pajak penghasilan badan masih berlangsung (Becker \& Fuest, 2012; Sanz-Córdoba, 2019; Suzuki, 2014). Penelitian ini menunjukkan penurunan tarif pajak penghasilan badan mengakibatkan penurunan rasio modal saham bank.

\section{Telaah Literatur dan Pengembangan Hipotesis}

Capital structure irrelevant theorem menyatakan (1) jika tidak ada pajak, nilai perusahaan tidak dipengaruhi oleh struktur modal, dan (2) jika pemerintah memberikan subsidi pajak dalam bentuk penghematan pajak dari utang (debt tax saving), nilai perusahaan dipengaruhi oleh bobot utang pada struktur modal (Modigliani \& Miller, 1958). Semakin besar bobot utang pada struktur modal, semakin besar subsidi pajak dari pemerintah, dan semakin besar nilai perusahaan.

Walaupun penambahan utang meningkatkan perolehan subsidi pajak dari pemerintah, penambahan nilai perusahaan tidak berbentuk linier melainkan U-Shape terbalik (Modigliani \& Miller, 1963). Pada gambar 2 dapat dilihat titik optimal nilai perusahaan terjadi ketika manfaat marjinal dari tambahan subsidi pajak sama dengan biaya marjinal kebangkrutan (financial distress cost) dari penambahan utang.

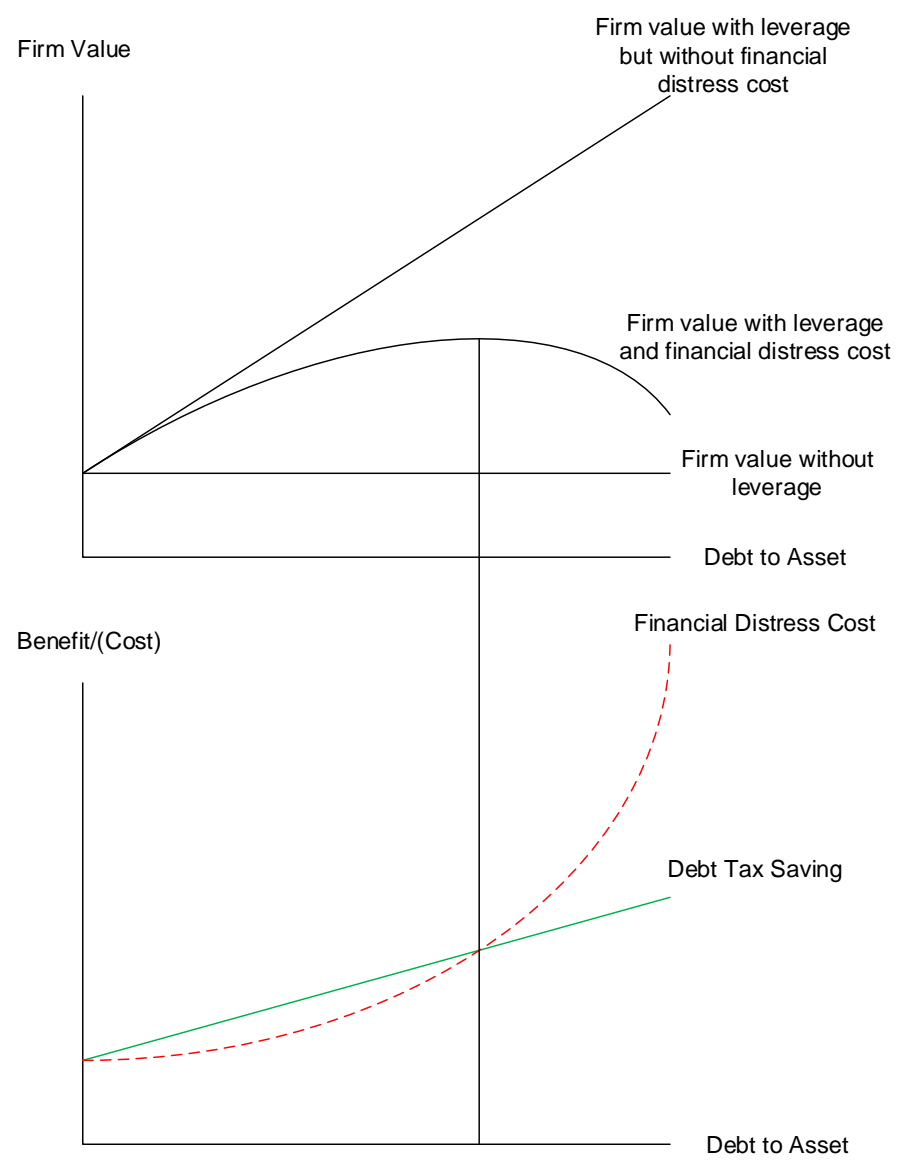

Gambar 2. Hubungan struktur modal dan nilai perusahaan.

Sumber: Modigliani dan Miller (1963) dimodifikasi Teja (2019) 
Studi Akuntansi \& Keuangan Indonesia

Titik optimal ketika manfaat marjinal dari tambahan subsidi pajak sama dengan biaya marjinal kebangkrutan pada perusahaan keuangan dan non-keuangan berbeda. Pada perusahaan keuangan, rasio utang terhadap modal saham sebesar delapan sampai sepuluh menunjukkan kondisi yang sehat. Lain halnya pada perusahaan non-keuangan, rasio utang terhadap modal sebesar empat menunjukkan perusahaan secara teknis telah mengalami kebangkrutan.

Walaupun titik optimal penggunaan utang dari perusahaan keuangan dan non-keuangan berbeda, Heckemeyer dan De Mooij (2017) menemukan perubahan tarif pajak penghasilan badan tidak mempengaruhi bias perusahaan keuangan dan non-keuangan terhadap penggunaan utang. Dengan demikian, teori struktur modal Modigliani dan Miller (1958) dan Modigliani dan Miller (1963) dapat diterapkan pada perusahaan keuangan.

Heider dan Ljungqvist (2015) membahas static dan dynamic capital structure trade-off model. Model static menyatakan perusahaan akan menambah tingkat utang sampai tambahan marjinal manfaat dari penghematan pajak sama besar dengan tambahan marjinal biaya kebangkrutan. Ketika tarif pajak penghasilan badan dinaikan, manfaat dari penghematan pajak dari sumber dana utang akan meningkat. Dengan demikian, peningkatan tarif pajak penghasilan badan akan meningkatkan penggunaan utang oleh perusahaan.

Pada model static, ketika tarif pajak penghasilan badan diturunkan sehingga tambahan marjinal penghematan pajak lebih kecil daripada tambahan marjinal biaya kebangkrutan, perusahaan akan menurunkan tingkat utangnya. Penurunan tingkat utang akan meningkatkan nilai perusahaan.

Pada model dynamic, ketika tarif pajak penghasilan badan diturunkan, pemegang saham tidak akan menurunkan tingkat utang. Alasan pemegang saham adalah penurunan tingkat utang akan menurunkan nilai opsi gagal bayar (option to default) dari pemegang saham (Fischer, Heinkel, \& Zechner, 2016). Penurunan nilai opsi gagal bayar akan meningkatkan nilai pemegang surat utang. Peningkatan nilai pemegang surat utang merugikan pemegang saham karena pemegang surat utang dapat mengambil seluruh nilai dari pemegang saham (Admati, Demarzo, Hellwig, \& Pfleiderer, 2018; Leland, 2016).

Berdasarkan pembahasan diatas, penurunan tarif pajak penghasilan badan dapat berpengaruh terhadap modal saham bank. Oleh karena itu, hipotesis yang diajukan adalah:

H1. Penurunan tarif pajak penghasilan badan berpengaruh terhadap modal saham bank.

Return on Assets (ROA) merupakan proxi dari keuntungan bank. Peningkatan keuntungan membantu peningkatan modal saham bank. Gross Loan to Deposit Ratio (LDR) merupakan efektifitas bank dalam menyalurkan dana. Gross $L D R$ yang tinggi berpengaruh pada keuntungan bank dan modal saham bank. Nonperforming Loan (NPL) pada waktunya akan dihapus buku (write-off) dan menjadi kerugian dari bank. Semakin besar NPL mengharuskan bank mempunyai modal saham yang lebih besar.

Tabel 1. Rangkuman hipotesis dan pengaruhnya terhadap modal saham bank

\begin{tabular}{lcc}
\hline \multicolumn{1}{c}{ Variable } & Simbol & Pengaruh pada modal saham bank \\
\hline Perubahan tarif pajak penghasilan badan & taxchg & $+/-$ \\
Perubahan ROA & ROA & + \\
Perubahan gross Loan to Deposit Ratio & grossLDR & + \\
Perubahan Non Performing Loan & NPL & + \\
\hline
\end{tabular}


Studi Akuntansi \& Keuangan Indonesia

\section{Metode Penelitian}

Data penelitian diunduh dari S\&P Capital IQ. Sampel penelitian adalah bank di Indonesia yang tercatat sebagai perusahaan publik pada tahun 2008-2010. Periode waktu ini selaras dengan penurunan tarif pajak penghasilan badan. Pada tahun 2008 tarif pajak adalah 30\%, 2009 turun 2\% menjadi 28\%, dan tahun 2010 turun 3\% menjadi 25\%. Dari data S\&P Capital IQ, terdapat 19 bank yang memiliki laporan lengkap. Kriteria pemilihan bank pada S\&P Capital IQ disajikan pada tabel 2.

Tabel 2. Laporan pemilihan bank.

\begin{tabular}{ccc}
\hline No & Kriteria & Hasil \\
\hline 1 & Lokasi geografi & Indonesia \\
2 & Klasifikasi industri & Bank \\
3 & Jenis surat berharga & Saham Publik \\
\hline
\end{tabular}

Periode waktu dari sampel sangat singkat yaitu tahun 2008-2010. Dengan demikian metode statistik yang lebih tepat adalah metode statistik regresi cross-section. Variabel terikat adalah perubahan rasio modal saham bank terhadap total aset bank (etachg). Rasio modal saham bank terhadap total aset bank dipilih karena rasio ini adalah rasio yang paling dekat dengan rasio kecukupan modal (CAR - Capital Adequacy Ratio). Pembahasan kesehatan bank umumnya menggunakan ukuran rasio kecukupan modal bukan rasio utang terhadap total aset. Variabel bebas adalah perubahan tarif pajak penghasilan dari tahun 2008 ke 2009 dan tahun 2009 ke 2010 (taxchg). Variabel kendali adalah perubahan Return on Asset (ROA), gross Loan to Deposit Ratio (grossLDR), dan perubahan rasio Non-Performing Loan (NPL).

Model empiris dari pengaruh penurunan tarif pajak penghasilan badan terhadap modal saham bank adalah:

etachg $_{i}=\alpha+\beta_{1} \operatorname{taxchg}_{i}+\varepsilon$

etach $_{i}=\alpha+\beta_{2}$ ROA $_{i}+\beta_{3}$ grossLDR $_{i}+\beta_{4} N P L_{i}+\varepsilon$

etachg $_{i}=\alpha+\beta_{1} \operatorname{taxchg}_{i}+\beta_{2}$ ROA $_{i}+\beta_{3} \operatorname{grossLDR}_{i}+\beta_{4} N P L_{i}+\varepsilon$

Dimana etachg mengacu pada perubahan rasio modal saham bank, taxchg mengacu pada perubahan tarif pajak penghasilan, gross $L D R$ mengacu pada perubahan gross Loan to Deposit Ratio, dan NPL mengacu pada perubahan Non Performing Loan. Semua perubahan mengacu pada perubahan relatif tahun sebelumnya. $\mathrm{i}=$ mengacu pada perusahaan dan $\varepsilon$ mengacu pada error dari regresi.

\section{Hasil dan Diskusi}

\section{Hasil Statistik Deskriptif}

Pada tabel 3 disajikan rata-rata deskriptif dari sampel. Pembahasan statistik deskriptif ditujukan untuk memahami karakteristik keuangan dari sampel penelitian. Perubahan rata-rata modal saham bank (etachg) relatif sangat kecil yaitu 0.0021 dengan standar deviasi 0.015. Perubahan ini selaras dengan perubahan Return on Asset (ROA) sebesar 0.0013. Gross Loan to Deposit Ratio dan NPL mempunyai nilai rata-rata yang negatif. Nilai ini akan dikonfirmasi melalui analisis regresi.

Tabel 3. Statistik Deskriptif

\begin{tabular}{lcccc}
\hline \multicolumn{1}{c}{ Variable } & Simbol & $\mathbf{n}$ & Mean & Standar Deviasi \\
\hline Perubahan modal saham bank & etachg & 38 & 0.0021 & 0.0158 \\
Perubahan tarif pajak penghasilan badan & taxchg & 38 & -0.0250 & 0.0051 \\
Perubahan ROA & ROA & 38 & 0.0013 & 0.0033 \\
Perubahan gross Loan to Deposit Ratio & grossLDR & 38 & -0.0227 & 0.0687 \\
Perubahan Non Performing Loan & NPL & 38 & -0.0223 & 0.5689 \\
\hline
\end{tabular}




\section{Studi Akuntansi \& Keuangan Indonesia}

\section{Hasil Pengujian Hipotesis dengan Regresi Cross-Section}

Pada tabel 4 disajikan hasil regresi cross-section. Variabel pada model 1 dan model 2 secara umum tidak signifikan. Ketika seluruh variabel disatukan pada model 3, seluruh variabel menjadi signifikan pada alpha $1 \%$ kecuali Non Performing Loan yang signifikan pada alpha $10 \%$. Koefisien perubahan tarif pajak penghasilan badan adalah positif. Mengingat data yang dimasukan adalah penurunan tarif pajak penghasilan badan, koefisien positif menyatakan penurunan tarif pajak penghasilan badan mengakibatkan penurunan rasio modal saham terhadap total aset. Variabel kendali secara umum memberikan hasil yang konsisten dengan prediksi. Return on Asset, Gross Loan to Deposit Ratio dan Non Performing Loan (NPL) mempunyai hubungan yang positif dengan rasio modal saham bank.

Tabel 4. Hasil regresi cross-section

\begin{tabular}{|c|c|c|c|}
\hline Keterangan & Model 1 & Model 2 & Model 3 \\
\hline Variabel terikat & etachg & etachg & etachg \\
\hline \multicolumn{4}{|l|}{ Variabel bebas } \\
\hline taxchg & 0.0877 & & $1.9026 * * *$ \\
\hline ROA & & $1.9826^{* *}$ & $2.6459 * * *$ \\
\hline grossLDR & & 0.0399 & $0.1279 * * *$ \\
\hline NPL & & 0.0036 & $0.0079 *$ \\
\hline constant & 0.0043 & -0.0003 & $0.0466 * * *$ \\
\hline $\mathrm{n}$ & 38 & 38 & 38 \\
\hline $\mathrm{R}^{2}$ & 0.0008 & 0.2239 & 0.3992 \\
\hline
\end{tabular}

Keterangan: $* * *, * *, *$ mewakili alpha $1 \%, 5 \%$, dan $10 \%$.

\section{Diskusi}

Hasil penelitian menunjukkan penurunan tarif pajak penghasilan badan mengakibatkan bank di Indonesia mengalami penurunan rasio modal saham bank terhadap total aset bank. Bank mengkompensasi penurunan tarif pajak penghasilan badan dengan meningkatkan utang sehingga nilai manfaat penghematan pajak dari utang (debt tax saving) dapat dipertahankan. Penurunan tarif pajak mempunyai pengaruh pada penurunan rasio modal saham terhadap total aset. Hasil penelitian ini konsisten dengan hasil penelitian dari Gambacorta, Ricotti, Sundaresan, dan Wang (2018). Mereka menemukan bank di Italia meningkatkan penggunaan utang ketika tarif pajak penghasilan diturunkan.

Mengingat penurunan tarif pajak penghasilan badan di Indonesia terjadi bersamaan dengan krisis sub-prime mortgage tahun 2008-2009 di Amerika Serikat, bank seharusnya lebih memperhatikan aspek kelangsungan hidup perusahaan. Oleh karena itu, bank sebaiknya tidak berupaya mendapatkan tambahan manfaat dari subsidi pajak dari pemerintah melalui penggunaan utang yang lebih besar.

Peningkatan modal saham bank yang ditunjukkan oleh statistik deskriptif terjadi karena keuntungan perusahaan yang semakin tinggi. Bank mengabaikan resiko eksternal dari krisis subprime mortgage dengan melakukan ekspansi untuk memanfaatkan inklusi keuangan di Indonesia yang masih rendah.

\section{Kesimpulan, Implikasi, dan Keterbatasan}

Penelitian ini ditujukan untuk memahami pengaruh penurunan tarif pajak penghasilan badan pada modal saham bank di Indonesia. Hasil pengujian hipotesis dengan menggunakan analisa regresi cross-section menunjukkan penurunan tarif pajak penghasilan mengakibatkan rasio modal saham bank terhadap total aset bank mengalami penurunan. Penurunan $1 \%$ tarif pajak penghasilan mengakibatkan penurunan rasio modal saham bank terhadap total aset bank sebesar $1.90 \%$. Temuan ini menunjukkan bank mengkompensasi penurunan tarif pajak penghasilan badan dengan utang yang lebih besar sehingga manfaat pajak dari utang (debt tax saving) dapat dipertahankan. Penurunan tarif pajak penghasilan badan mengakibatkan penurunan rasio modal saham bank terhadap total aset. 
Studi Akuntansi \& Keuangan Indonesia

Implikasi penelitian ini adalah bagi Bank Indonesia harus menerbitkan regulasi untuk menghambat kecenderungan bank untuk mengambil risiko dan memperkuat modal saham bank.

Keterbatasan penelitian ini adalah penelitian hanya berfokus pada rasio keuangan dari bank. Analisis faktor eksternal, yaitu tingkat inklusi keuangan dan situasi krisis dapat memberikan pemahaman yang lebih baik pada strategi keuangan dari bank ketika tarif pajak penghasilan badan diturunkan. Pemerintah Indonesia menurunkan lagi tarif pajak penghasilan badan pada tahun 2020-2022 dari 25\% menjadi 20\%. Disarankan untuk membuat penelitian serupa untuk memahami perbedaan pengaruh perubahan tarif pajak penghasilan badan tahun 2008-2010 dan tahun 2020-2022.

\section{Daftar Pustaka}

Admati, A. R., Demarzo, P. M., Hellwig, M. F., \& Pfleiderer, P. (2018). The Leverage Ratchet Effect. Journal of Finance, 73(1), 145-198. https://doi.org/10.1111/jofi.12588

Afrianto, H. F. (2018). Tax Competition for Foreign Direct Investment in ASEAN : Is Corporate Income Tax Harmonization the Solution? 2018, 1085-1118. https://doi.org/10.18502/kss.v3i11.2832

Becker, J., \& Fuest, C. (2012). Transfer pricing policy and the intensity of tax rate competition. Economics Letters, 117(1), 146-148. https://doi.org/10.1016/j.econlet.2012.04.061

Beirne, J., \& Friedrich, C. (2017). Macroprudential policies, capital flows, and the structure of the banking sector. Journal of International Money and Finance, 75, 47-68. https://doi.org/https://doi.org/10.1016/j.jimonfin.2017.04.004

Bremus, F., Schmidt, K., \& Tonzer, L. (2020). Interactions between bank levies and corporate taxes: How is bank leverage affected? Journal of Banking and Finance, 118, 105874. https://doi.org/10.1016/j.jbankfin.2020.105874

Fischer, E. O., Heinkel, R., \& Zechner, J. (2016). American Finance Association Dynamic Capital Structure Choice: Theory and Tests Authors ( $s$ ): Edwin O. Fischer, Robert Heinkel and Josef Zechner Source : The Journal of Finance, Vol. 44 , No . 1 ( Mar., 1989 ), pp . 19-40 Published by : Wiley for t. 44(1), 19-40.

Gambacorta, L., Ricotti, G., Sundaresan, S. M., \& Wang, Z. (2018). The Effects of Tax on Bank Liability Structure. SSRN Electronic Journal, 138(July). https://doi.org/10.2139/ssrn.2946984

Gordon, M. J. (1963). Optimal Investment and Financing Policy. Journal of Finance, 27(1), 97-102.

Heckemeyer, J. H., \& De Mooij, R. A. (2017). Taxation and corporate debt: Are banks any different? National Tax Journal, Vol. 70, pp. 53-76. https://doi.org/10.17310/ntj.2017.1.02

Heider, F., \& Ljungqvist, A. (2015). As certain as debt and taxes: Estimating the tax sensitivity of leverage from state tax changes. Journal of Financial Economics, 118(3), 684-712. https://doi.org/10.1016/j.jfineco.2015.01.004

Horváth, B. L. (2020). The interaction of bank regulation and taxation. Journal of Corporate Finance, 64(March), 101629. https://doi.org/10.1016/j.jcorpfin.2020.101629

Kato, H. (2015). The importance of government commitment in attracting firms: A dynamic analysis of tax competition in an agglomeration economy. European Economic Review, 74, 57-78. https://doi.org/10.1016/j.euroecorev.2014.11.008

Keen, M. (2011). The Taxation and Regulation of Banks. IMF Working Papers.

Leland. (2016). American Finance Association Corporate Debt Value, Bond Covenants , and Optimal Capital Structure Author ( $s$ ): Hayne E. Leland Source: The Journal of Finance, Vol . 49 , No . 4 ( Sep ., 1994 ), pp . 1213-1252 Published by: Wiley for the American Fin. 49(4), 1213-1252.

Martin-flores, J., \& Moussu, C. (2017). Is bank capital sensitive to a tax allowance on marginal equity? (2016), 325357. https://doi.org/10.1111/eufm.12163

Modigliani, F., \& Miller, M. H. (1958). The Cost of Capital, Coorporate Finance and the theory of investment. The 
Studi Akuntansi \& Keuangan Indonesia

American Econoic Review, 568(3), 261-297.

Modigliani, F., \& Miller, M. H. M. (1963). American Economic Association Corporate Income Taxes and the Cost of Capital : A Correction. American Economic Review, 53(3), 433-443. https://doi.org/10.1126/science.151.3712.867-a

Sanz-Córdoba, P. (2019). The role of infrastructure investment and factor productivity in international tax competition. Economic Modelling, (September 2018). https://doi.org/10.1016/j.econmod.2019.05.003

Schepens, G. (2016). Taxes and bank capital structure. Journal of Financial Economics, 120(3), 585-600. https://doi.org/10.1016/j.jfineco.2016.01.015

Suzuki, M. (2014). Corporate effective tax rates in Asian countries. Japan and the World Economy, 29, 1-17. https://doi.org/10.1016/j.japwor.2013.11.001

Teja, A. (2019). TAX RATE AND NON-DEBT TAX SHIELD. Jurnal Riset Manajemen Dan Bisnis (JRMB) Fakultas Ekonomi UNIAT, 4(2), 257-268. https://doi.org/10.36226/jrmb.v4i2.261

Ummah, B. B., Nuryartono, N., \& Anggraeni, L. (2012). Analisis inklusi keuangan dan pemerataan pendapatan di Indonesia. Jurnal Ekonomi Dan Kebijakan Pembangunan, 1(2), 111-135.

Undang-Undang Republik Indonesia. (2008). Undang-Undang Nomor 36 Tahun 2008 : Perubahan Keempat atas Undang-Undang No. 7 Tahun 1983 Tentang Pajak Penghasilan. Kantor Pajak, 49, 69-73. 